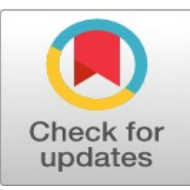

\title{
The health behaviors' modification for controlling and prevention of diabetes mellitus by using promise model at premruthai pravate community Bangkok
}

\author{
Thipapan Sungkhapong ${ }^{1 *}$, Poosadee Prommete ${ }^{2}$, Namthip Martkoksoong ${ }^{3}$, Boonsri Kittichottipanich ${ }^{4}$
}

1,2, 3,4 Instructor of Nursing and Health College, Suan Sunandha Rajabhat University, Thailand

\section{Key Words:}

Health Promotion

Diabetes

Participatory Action Research

Received: 27 May 2016

Accepted: 21 August 2016

Published: 25 October 2016

\begin{abstract}
The participatory action research aims to study how to change health behavior about the ability of self- efficacy, self regulation and self-care for prevention and control of diabetes with PROMISE model. The sample was subjects at risk and patients with diabetes and high blood pressure. A total of 28 people from the Premruthi community 20 at Prawet Bangkok were chosen. Most were female having lower education. Entitled to healthcare Gold in Bangkok. The Vulnerable groups and groups with diabetes and high blood pressure were 51.3 percent. Accounted for 10.6 per cent of the risk factors that is important. Obese / BMI was 24.7 percent. Higher risk behavior is eating spicy food ( sweet, sour , salty) 40.7 percent, Lack of exercise, stress, 12.7 percent to 28 percent, Genetic risk is 23.3 percent and 12.7 percent were smokers. The results showed that after receiving behavior modification, have efficacy in their health behavior (Self-efficacy), Self-regulation and Self-care better than before the event: 92.3 percent, 90.0 and 96.6 of the participants, respectively. It is a change in a better direction. And blood pressure dropped from 86 percent to 36 percent, weight loss and BMI decreased by 20.7 percent. That health status has changed to the better. Most members were satisfied with the high level of 97.3 per cent suggested in the project next time. This research focused on the development of activities that encourage participants to have the skills and knowledge through practical action. Making sustainable approach is organized in accordance with activities that blend into everyday life. Obtaining social support to encourage volunteerism, good health care personals and some extra incentive to participate. These factors resulted in trust and cooperation from members and communities of Practice to foster good health.
\end{abstract}

\section{INTRODUCTION}

Diabetes is a chronic, non-communicable disease that is a major public health problem in the world, including Thailand. The current situation in diabetes incidence is increasing. Data from the International Diabetes Federation were obtained [1]. The situation was reported to be 285 million people with diabetes worldwide, and has estimated that a significant number of people with diabetes worldwide will be more than 435 million people in the year 2030 if no action is taken to prevent and control efficiency. In Thailand people are facing diabetes. Data from the Bureau of Policy and Strategy Ministry of Public Health meet people died from diabetes in the year 2009, about 7,019 people, or about 19 people per day, and a survey of the health status of people aged 15 years and over Thailand 2nd Year 1996-1997 compared to the three years from 2546 to 2547, prevalence increased

\footnotetext{
${ }^{*}$ Corresponding author: Thipapan Sungkhapong

†Email: thipapan.su@ssru.ac.th
} 
from 4.4 percent to 6.9 percent for the fourth time as last time. Year 2551-2552 found the same prevalence of diabetes that is 6.9 percent. Diabetes is a common cause of illness and premature death. 1 of complications to the eyes, kidneys, nervous system, heart and stroke. And a survey of the health status of Thailand found that one in three times, four of those with diabetes do not know they have diabetes before. For those who have been diagnosed by a physician as having diabetes, 3.3 percent were not treated. And those who were treated with only had 28.5 percent of the control of blood sugar levels in less than 126 milligrams per deciliter. So for those who are at risk from diabetes and asymptomatic, reducing risk factors and treatment of early stage as well as encouraging people with diabetes to take care of themselves properly, so it is a measure that will reduce and slow down the disease and the effects thereof. Diabetes is caused by several common factors that can be prevented. Even with diabetes, obesity can also prevent complications by behavior modification, eating diminishes the fat diet and exercise can prevent dibetes mellitus and cardiovascular disease [2,3]. By helping vulnerable groups and people with diabetes understand and realize the threat of disease, knowing the causes of disease, knowing the early warning signs of diabetes, knowing how to prevent or delay diabetes, learning selfcare on diabetes control and preventing complications that arise as a consequence can help. As a result of the self-care behaviors of people with diabetes last year 2008 -2011 on the basis of 3 self is to allow people to engage in self-care (Self-care), Self (Self-regulation) continued to be healthy with a belief in their own ability (Self-efficacy) to modify behavior (Behavior modification) process that modifies the mental and physical state or behavior inside and outside. To maintain good health habits as a way of life of each individual, process consisted of the following steps:

1. Positive reinforcement - positive reinforcement.

2. Result based management - principles for the achievement of the task.

3. Optimism - The optimistic.

4. Motivation - motivating.

5. Individual or client center - seizing people at the center.

6. Self- esteem - Principles build self-esteem.

The efficacy of a behavioral change, Self regulation and self care was more than before the project, and the most satisfaction of the program. Therefore, the implementation of the project was to promote learning how to prevent diabetes complications. Thus the program for promoting the health behaviors for preventing and controlling diabetes mellitus operates by $3 \mathrm{~S}$ : Self awareness, Self regulation and Self care. This results in reducing complication, morbidity and mortality rates from diabetes mellitus in Premruthai Pravate Community Bangkok.

\section{Objectives}

The members who attended this program have changed as follows:

1. Increased efficacy in behavior control and prevention of diabetes.

2. Increased self regulation behavior control and prevention of diabetes.

3. Increased the self-care behaviors for controlling and prevention of diabetes mellitus.

\section{METHODOLOGY}

\section{Research Design and Sample}

The research was designed by using Participatory Action Research (PRA) with 28 purposive sampling at Premruthai Pravate Community Bangkok, who were at risk for diabetes or high blood pressure. They enrolled in the participatory activity with PROMISE Model 
during January 2013 - May 2013, for creating 3 S (self awareness, self regulation, and self care) as in the step figure 1.

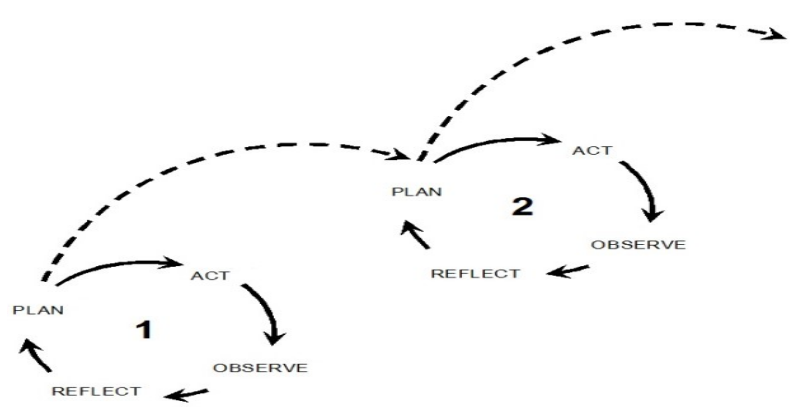

FIGURE 1. Shows a spin around of the operating part for prevention and control of Diabetes Mellitus

The duration of the operation was from January 6, 2558 - July 31, 2558. By the method of participatory learning with PROMISE Model. Research design was based on 4-time meeting, each time consisted of 4 steps (panning, action, observe and reflect). The main activities in behavior modification were training awareness about health behavior change, principle of daily food consumption, exercise relieves stress and empowerment for self care in the prevention and control of diabetes and hypertension and home visit nursing. The participants have recorded health activities into their record book.The plan of activities for promoting health and behavioral modification each time were in the following order:

\section{The first meeting activity}

- Participation for creating self awareness and participation in changing their behavior.

- Initial health assessment activities.

- Group discussion, participation in solving problems of the participants.

\section{The second meeting activity}

- To improve understanding of health behavior modification.

- Training activities to educate about health behavior modification in the diet, exercise and the empowerment of the self to be self-regulatory.

-Group discussion demonstration and practicing .

\section{The third meeting activity}

-Promoting knowledge to use in $3 \mathrm{~S}$ (self-awareness, self regulatory and self-care).

- Physical activity.

- Activity for modification of health behaviore.

- Evaluation activities individually by phone and home visits by nurse.

\section{The fouth meeting activity}

- Assessment activity after participating pretest and posttest.

- Summary of the activities and the benefits of participating.

- Discussion and Observation, Awards and souvenirs.

- Closed the program. 


\section{Ethics}

The research takes into account the right of the sample. The objectives of the research process, research and a period of research are the clarification of the right to accept or refuse to participate in this research without affecting in any way the lesson. In addition, during the research if the samples do not wish to participate in the research completed on schedule can be terminated without affecting the learning of information obtained from this research as confidential. Presentation of data will be presented in an overview. There is no disclosure of the name and surname when samples are willing participants. The research sample signed a consent form to participate in the study (informed consent form).

\section{RESULTS}

From the risk group with diabetes and high blood pressure 51.3 percent accounted for 10.6 per cent of the risk factors as important. Obese / BMI had 24.7 percent higher risk behavior of eating spicy food ( sweet, sour, salty) 40.7 percent. Lack of exercise, stress, 12.7 percent to 28 percent, Genetic risk is 23.3 percent and 12.7 percent were smokers. The results showed that after receiving behavior modification have efficacy in their health behavior (Self-efficacy), Self-regulation and Self-care better than before the event: 92.3 percent, 90.0 and 96.6 of the participants, respectively. It is a change in a better direction. And blood pressure dropped from 86 percent to 36 percent, weight loss and BMI decreased by 20.7 percent. That health status has changed to the better. Most members were satisfied with the high level of 97.3 per cent The behavior changed after program with $3 \mathrm{~S}$ was changed as follows:

1. That the efficacy of behavior changed their health than before, increasing participation of 26 people, representing 92.8 percent of the total.

2. Directing the behavior of people increased over the first 25 participants, representing 89.2 percent of the total.

3. Has the self-care behaviors. The increase over the first 26 people to attend the event, 92.8 percent of the total.

Health outcomes of participants in the study were change in body weight, body mass index (BMI) and blood pressure changed to the better direction.

\section{Satisfaction of the Program}

The satisfaction of participants in this program was at the high level of 89.2 percent .

\section{Data Analysis from Qualitative Data}

By analyzing qualitative data about patterns of care in the prevention and control of diabetes on a daily basis that involves behavior modification, health promotion, daily eating, exercise and stress management, the study concluded by telling the members about controlling diabetes risk by what, when and how. The result concluded that most should eat breakfast, eating vegetables should be increased, try not to eat sweets, do not eat fruits or sweet sauce by adding some seasoning. Do not add a little sugar in every meal. Regularly eating fish, salted fish, salted pickles to eat a long time. As the example from interview in following:

- Eat up some chilli, fresh vegetables, fish and rice ladle 2 / meal of chicken, pork, eat regularly. All vegetables with chilli. Do not eat dessert. I do not eat sweet fruit.

- Do not drink coffee, eat lunch at noon to eat vegetables, chilli, vegetable soup, cold soup; does not eat fried foods, salty, not sweet, not really. 
- 8:00 pm. I had breakfast porridge, fresh meat coming for two years, I do not like eating the fresh salty second term.

- Eat breakfast, eat three fried rice ladles to scoop the lower one in eating salty.

TABLE 1. Numbers and percentages of the sample ( $\mathrm{n}=28$ patients)

\begin{tabular}{lccccc}
\hline Data & $\mathbf{N}$ & $\%$ & Data & N & $\%$ \\
\hline Age (yrs) & & & sex & & \\
$40-49$ & 8 & 28.6 & Female & 20 & 71.4 \\
$50-59$ & 8 & 28.6 & male & 8 & 28.6 \\
$>60$ & 12 & 42.8 & After the Program Weight change & & \\
Education & & & & & \\
High school,Vocational & 15 & 53.6 & Diminished & 18 & 50.0 \\
Bachelor & 13 & 46.4 & Unchanged & 7 & 25.0 \\
Right of Medical Care & & & Increased & 3 & 10.7 \\
Gold Card & 12 & 42.8 & Blood pressure change & & \\
Social Security & 14 & 50.0 & Diminished & 18 & 64.2 \\
Government & 2 & 7.2 & Unchanged & 7 & 25.0 \\
& & & Increased & 3 & 10.7 \\
The risk for diseases (more than one risk) & & & Blood Glucose Level & & \\
Diabetes Mellitus & 25 & 89.2 & Diminished & 24 & 85.7 \\
Hypertension & 15 & 53.0 & Unchanged & 4 & 14.2 \\
Cerebovascular & 8 & 28.5 & Increased & no & 0.0 \\
Obesity & 20 & 71.4 & Satisfaction of Program & & \\
Sample with disease & & Moderate & 3 & 10.7 & \\
Diabetes Mellitus & 20 & 71.4 & High & 25 & 89.2 \\
Hypertension & 14 & 50.0 & & & \\
Cerebovascular & 8 & 12.5 & & & \\
Obesity & 8 & 28.6 & & & \\
\hline
\end{tabular}

\section{DISCUSSION}

The result from this research shows that the biodata of samples mostly $71.4 \%$ is female and 28.6 is male. This result is according to the study of Intharakamhang [4] "Study of Administration and Evaluation to Health Adaptation of Health Center in Bangkok. 21 projects in 2009 found that DM person is female $67.68 \%$ and male is $32.32 \%$ compared with World population (2015) DM person is female 199.5 million and male is 215.2 million, contrasted with this study and finding of Intharakamhang [4] study It may be different from race context in many areas including economic, life style, nutrition, exercise, sleep, rest and working. The sampling' s BMI decreased 50\%, BP decreased $85.7 \%$. This result is according to the study of Intharakamhang [4] "Study of administration and evaluation to The health adaptation of Health Center in Bangkok. 21 projects in 2009 found that participation group decreased BMI 65.36\%, BP 61.45\%, BS(DTX) 59.49\%, means that they have modified behavior and must have good self awareness so they can get self regulation at last they can self manage to prevent complication both acute and chronic complication meaning that they got self efficacy. The self-management can improve health status [5]. The self management program to control and prevent DM in daily life found that participants should eat more vegetables and stop to eat dessert and all the sweet fruits cooking, without sugar or just a little bit and daily eat fish. This result is also according to the study of Sumnuk [6] "Study of effective program modification of behavior of people health risk group to hypertension in community, Pakpanung district, Nakornsrithamaraj " which found that participation got more knowledge, activities and exercises. "Study of behavior modification in risk group to DM and hypertension" found that means of self management behavior about eating exercise increase after the study is significant. The most common lifestyles in Thailand which risk metabolic syndrome were reduced physical activity, lack of self control, being overly courteous by not eating a healthy diet. 4 The lack of need to control their 
food intake is the key to prevention $[7,8]$. Thus in this program, the most participants increased the self regulation. That is the one guideline for controlling and prevention of the chonic disease.

\section{CONCLUSION AND RECOMMENDATIONS}

This research used participatory action research to promote and modify health behaviors which focused on the development of activities that encourage participants to have the skills and knowledge through practical action. Make sustainable approach is organized in accordance with activities that blend into everyday life. Obtaining social support to encourage volunteerism, good personal health care and some extra incentive to participate. These factors resulted in trust and cooperation from members and communities of healthy community.

\section{ACKNOWLEDGMENT}

This study was supported by the grant from Research and Development Institute, and Funding for Personnel Development Center, Suan Sunandha Rajabhat University (SSRU), Thailand. The researcher gratefully acknowledges SSRU and College of Nursing and Health.

\section{REFERENCES}

1. Falentin F. The metabolic syndrome an Overview: New scientific evidence suggests that a healthy lifestyle might be the best treatment alternative and prevention strategy. Nutritional Perspectives: Journal of the Council on Nutrition. 2010; 33(2): 13-21.

2. Haynes D, Pruitt R, Watt P, Parker V, Price KM. Controlling metabolic syndrome in the Latino population: Support for current guidelines. Hispanic Health Care International. 2010; 8(2): 85-92. DOI: 10.1891/1540-4153.8.2.85

3. Wannapornsiri C, Lekchupol N. Lifestyle risk of syndrome among Thai adult in rural area. Thai Red Cross Nursing Journal. 2015; 8(2): 1-15.

4. Intharakamhang A. Study of administration and evaluation to health adaptation of health center in Bangkok. Behavior Science Research Institute, Srinakharinwirote University, Bangkok: TH, 2010.

5. Lorig KR, Sobel DS, Stewart AL, Brown Jr BW, Bandura A, Ritter P, Holman HR. Evidence suggesting that a chronic disease self-management program can improve health status while reducing hospitalization: A randomized trial. Medical Care. 1999; 37(1): 5-14. DOI: 10.1097/00005650-199901000-00003

6. Sumnuk NJ. Study of effective program modification behavior people health risk group to hypertension in community Pakpanung district Nakornsrithamaraj. Khon Kaen University, Khon Kaen: TH, 2011.

7. De Oliveira EP, McLellan KCP, De Arruda Silveira LV, Burini RC. Dietary factors associated with metabolic syndrome in Brazilian adults. Nutrition Journal. 2012; 11(1): 1-7. DOI: 10.1186/1475-2891-11-13

8. De Vos BC, Runhaar J, Bierma-Zeinstra SM. Effectiveness of a tailor-made weight loss intervention in primary care. European Journal of Nutrition. 2014; 53(1): 95-104. D0I: 10.1007/s00394-013-0505-y 